CITE AS: Chuquichambi Apaza, E. G., Corradi, G. B., Munar, E., \& RossellóMir, J. (2021). When Symmetric and Curved Visual Contour Meet Intentional Instructions: Hedonic Value and Preference. Quarterly Journal of Experimental Psychology. https://doi.org/10.1177/17470218211021593

\title{
When Symmetric and Curved Visual Contour Meet Intentional Instructions: Hedonic Value and Preference
}

\author{
Erick G. Chuquichambi ${ }^{1}$, Guido B. Corradi² ${ }^{2}$ Enric Munar ${ }^{1}$ and Jaume Rosselló-Mir ${ }^{1}$ \\ ${ }^{1}$ Human Evolution and Cognition Group (EvoCog), University of the Balearic Islands \\ Palma de Mallorca, Spain \\ ${ }^{2}$ Department of Psychology, Faculty of Education and Health, University Camilo José \\ Cela, Madrid, Spain
}

\section{Author Note}

Correspondence concerning this article should be addressed to Erick G. Chuquichambi, Human Evolution and Cognition Group (EvoCog), Faculty of Psychology, University of the 
Balearic Islands, Campus. Ctra. Valldemossa km 7’5. 07122 Palma, Balearic Islands, Spain. Email: erik.chuquichambi@uib.es

\begin{abstract}
Symmetry and contour take part in shaping visual preference. However, less is known about their combined contribution to preference. We examined the hedonic tone and preference triggered by the interaction of symmetry and contour. Symmetric/curved, symmetric/sharpangled, asymmetric/curved, and asymmetric/sharp-angled stimuli were presented in an implicit and explicit task. The implicit task consisted of an affective stimulus-response compatibility task where participants matched the stimuli with positive and negative valence response cues. The explicit task recorded liking ratings from the same stimuli. We used instructed mindset to induce participants to focus on symmetry or contour in different parts of the experimental session. We found an implicit compatibility of symmetry and curvature with positive hedonic tone. Explicit results showed preference for symmetry and curvature. In both tasks, symmetry and curvature showed a cumulative interaction, with a larger contribution of symmetry to the overall effect. While symmetric and asymmetric stimuli contributed to the implicit positive valence of symmetry, the effect of curvature was mainly caused by inclination toward curved contours rather than rejection of sharp-angled contours. We did not find any correlation between implicit and explicit measures, suggesting that they may involve different cognitive processing.

Keywords: symmetry, curvature, mindset, implicit, hedonic value, visual preference
\end{abstract}




\section{When Symmetric and Curved Visual Contour Meet Intentional Instructions: Hedonic Value and Preference}

Low-level visual features shape aesthetic visual preference, with a common set of features shared across cultures (Che et al., 2018). Research on basic visual features that predict aesthetic preference is quite dispersed, variably focusing on balance (Hübner \& Fillinger, 2016; Wilson \& Chatterjee, 2005), brightness (Graham et al., 2016), complexity (Güçlütürk et al., 2016; Nadal et al., 2010), contour (Gómez-Puerto et al., 2017; Munar et al., 2015), contrast (Dongen \& Zijlmans, 2017), proportion (Pittard et al., 2007), self-similarity (Street et al., 2016; Viengkham \& Spehar, 2018) and symmetry (Bertamini et al., 2013; Jacobsen \& Höfel, 2003; Pecchinenda et al., 2014), among others. While most studies consider these features in isolation, less is known about how interactions of features affect hedonic valuation and preference. As Makin (2017) stated, stimuluspreference law is likely to be twisted or modulated when another feature is also evaluated, explicitly or not. On the other hand, the specification to contrast the nomothetic versus the ideographic approach on aesthetic research (i.e. judgments at a group level vs. judgments at an individual level) seems to attain special relevance (Jacobsen \& Höfel, 2002). Consequently, more studies are needed in order to understand how these interacting features contribute to general and particular preference.

Early studies discussed the interaction between visual features to define formal measures of aesthetic preference (Birkhoff, 1932; Eysenck, 1941, 1968). These measures predict diverse relationships between features and preference. In the last decades, several studies further examined human preference for such interactions. Eisenman (1967), for instance, found preference for symmetry and simplicity, and suggested a rejection of complexity for asymmetrical shapes. In a following study, Eisenman and Gellens (1968) showed that complex shapes are preferred only in conjunction to symmetry, suggesting that symmetry tends to simplify complexity. In turn, Jacobsen and Höfel (2002) reported that symmetry, followed by complexity, shows the highest correlations with beauty. Likewise, Tinio and Leder (2009) found that symmetry is a 
stronger predictor of beauty than complexity, suggesting that the influence of complexity on aesthetic judgment is sensitive to massive familiarization, while the influence of symmetry is not. Complexity also was studied in conjunction to kind of contour. Silvia and Barona (2009) found that non-expert participants prefer curved rather than angular polygons both for simple and complex shapes. In turn, complex over simple polygons are preferred, both for curved and angular contours. However, these interactions changed depending on artistic expertise. Using node-link diagrams, Carbon et al. (2018) found that beauty is mostly based on curvature aspects at short presentation times, while complexity is considered when time is unrestricted, although the effect is in the opposite direction: the more complex the stimulus, the less liked.

Other studies used multidimensional stimuli to test the relationships between stimulus features and preference. Makin (2017) found preference for symmetrical over random arrangements, and blue over brown, although no difference was found between circles and squares. However, squares rather than circles were preferred for random arrangements. The interaction between sessions showed that preference for symmetry and preference for blue were significantly higher in the simple than in the combined session. Mayer and Landwehr (2018) suggested that the most determinants of aesthetic liking for abstract artworks are, in descending order, self-similarity, contrast, symmetry and complexity. However, the results of Studies 2 and 3 in their work did not support these results, especially in relation to expertise and landscape images. Further, the authors did not report the interactions between the four features, incorrectly assuming that all four measures contributed independently to aesthetic liking. According to Makin (2017), is unrealistic to assume that all the features from a specific stimulus are orthogonal and that their effects on preference are independent.

Furthermore, the effects of feature interactions on evaluations do not depend only on the stimulus characteristics. As has been widely proven at the detriment of the naive realism prospect (Ross \& Ward, 1996), a variety of goal-driven and framing factors influence the evaluation of perceptual features (Skov \& Nadal, 2019). Prior knowledge, expertise, context, cognitive 
demands, mental sets and instructions, among others, are variables whose effects need to be considered to better understand human preference. The manipulation of these factors, namely instructed mindsets and if-then rules (task-sets, from now on), are helpful to examine features evaluation, while facilitating performance and improving measurement quality as discussed below.

People use different strategies to better perform tasks. Both mindsets and task-sets are relevant in improving the readiness for a task, the persistence in its execution and the filtering of incidental (i.e. irrelevant) information (Fujita et al., 2007). Mindsets, understood as instructed proactive dispositions to focus on specific features to arrange task-sets, favour the narrowing of attention on task-relevant information and the tuning towards goal implementation (Armor \& Taylor, 2003; Gollwitzer, 2012; Gollwitzer \& Bayer, 1999). These mindsets (implemental mindsets by Gollwitzer \& Bayer, 1999) enhance the correspondence between attitudes and behaviour (Henderson et al., 2008). Interestingly, as mindsets imply different ways to process information (Gollwitzer, 2012), they are likely to influence our evaluations. Indeed, implemental mindsets seem to reduce the evaluative ambivalence toward unrelated attitude objects (Henderson et al., 2008). Like mindsets, task-sets, meant as stimulus-response mappings guiding execution, can be effectively implemented by instructions (Meiran et al., 2015). Recent findings reveal that novel instructions can immediately lead to an efficient and autonomous execution (Liefooghe \& Verbruggen, 2019). This proactive effect of the instructed task-sets has been interpreted as a form of automaticity without practice (Meiran et al., 2017).

The 'power' of instructions have been studied especially on Stimulus Response Compatibility (SRC) effects (e.g., Cohen-Kdoshay \& Meiran, 2007). In the case of affective SRC (aSRC), hedonic similarity between feature and response lead to stimulus-response compatibility (Fitts \& Deininger, 1954), while affective disparity lead to incompatibility. Instructed task-sets define compatibility-incompatibility mappings on the basis of the assumed valence of features and responses. This way, a better performance is expected when the valence of the feature and the 
valence of the response match, compared to when they mismatch (De Houwer \& Eelen, 1998). This effect can occur even when the affective valence of the feature is irrelevant for the task (De Houwer, 1998). Strikingly, when the instructed task-sets define the hedonic value of the response (e.g. to select a happy face when the stimulus is curved) the affective meaning attached to the response depends on this intention-based coding rather than on stimulus-response associations (Eder \& Rothermund, 2008). In other words, the cognitive representation of responses determines the attached valence and, therefore, the compatibility effects. If the compatibility conditions are constructed at the cognitive level (i.e. without the need of previous associations) it is possible to dispense with the block structure and the task-switching cost of the standard IAT (Implicit Association Test) (Greenwald et al., 1998). This way, the reliability and the validity of the measurement procedure tend to improve. This seems to be the case for the aSRC task used by Eder et al. (2013), on which our task is inspired. This variant of the IAT partially circumvent some of its major shortcomings, namely response recoding, category re-definition, task-switching drawbacks and sensibility to stimulus selection (Teige-Mocigemba et al., 2010).

In visual aesthetics, the experimental procedures have scarcely explored the role of instructions, with a few exceptions. Höfel and Jacobsen (2007a, 2007b) manipulated instructions to compare spontaneous and intentional processing of symmetric and asymmetric patterns. In contrast, a wide number of studies applied aSRC tasks (commonly referred to as implicit measures), often in combination with explicit counterparts. Most of these works used the IAT (Greenwald et al., 1998) to explore presumed implicit preference both for symmetry (Bertamini et al., 2013; Makin et al., 2012; Weichselbaum et al., 2018) or curvature (Palumbo et al., 2015), and for artistic or decorative paintings (Pavlović \& Marković, 2012), architectural styles (Mastandrea et al., 2011), design objects (Mastandrea \& Maricchiolo, 2014), and wallpaper patterns (Fu et al., 2019). Despite its valuable contribution to test hedonic tones attached to visual features, most studies share an unfortunate misunderstanding. To different degrees, they assume that the standard valence-IAT directly measures implicit or automatic preference. Instead, the valence- 
IAT, insofar as it is an aSRC task, indirectly measures the hedonic valuation from which preference and, more generally, aesthetic evaluation might stem (Becker et al., 2019). In fact, although Weichselbaum et al. (2018) interpreted IAT outcomes as "implicit preferences", they expressly warned in advance: "Note that the IAT effect does not directly reveal implicit preferences but show how strongly two concepts are related" (Weichselbaum et al., 2018; p.3). Likewise, Pavlović and Marković (2012) argued that the IAT effects reveal basic hedonic reactions on which, at least partially, the aesthetic assessments are based on. Overall, the evidence suggests that, although different evaluative judgments stem from a common hedonic value, they additionally engage different cognitive processes to different extent (Huang et al., 2020; Leder \& Nadal, 2014; Miller \& Hübner, 2020).

\section{The present study}

The current study aims to contribute to further understanding of hedonic responses and preference triggered by the interaction of visual symmetry and contour. Specifically, we use four types of patterns that combine two categories of symmetry (symmetric vs. asymmetric) and two categories of contour (curved vs. sharp-angled). On the one hand, the procedure is aimed to indirectly measure, with an aSRC task, the hedonic response triggered by the combined categories (i.e. curved-symmetric, curved-asymmetric, sharp-symmetric, sharp-asymmetric). On the other hand, it is planned to directly evaluate the explicit preference of the stimuli. We use intention-based instructions to sequentially induce two mindsets (e.g. symmetry and contour). Both the indirect and the explicit tasks have two parts. Participants are induced to focus in a feature (the relevant feature) in each part. For the aSRC task, we define two mutually complementary task-sets for each mindset in order to map the compatible and incompatible conditions (see the Procedure section). In this regard, it is crucial to keep in mind that these conditions were defined according to the hypothesized assumption that, when relevant for response selection, the symmetric category and the curved category would give rise to positive hedonic values, while negative valences would be coupled with asymmetric and sharp-angled 
features. Note that the stimuli used are bivalent, that is, they exhibit both symmetry and contour features. This bivalency, together with the instructed mindsets and task-sets, allows us to study participants' assessments using the same set of stimuli and constant response sets.

Together, the procedure outlined above aim to broaden our knowledge in four respects:

1. Since the hedonic values of symmetry and curvature are assumptions, the instructed task-sets should serve to test the predicted affective meaning for each of the four combined categories. If the compatibility/incompatibility mappings were confirmed, this would suggest that the expected hedonic values correspond to their actual values. On the other hand, the results will contribute to understand how the hedonic value for each category of the relevant feature change according to the category of the irrelevant feature.

2. Given that the hypothesized valences of the stimulus categories are irrelevant for the task at hand, the evidence of compatibility/incompatibility effects would suggest a high degree of automatism, both in processing and response implementation, of this hedonic value.

3. Mindsets could differently affect hedonic valuation and preference for symmetry and curvature. Given the fact that previous research has shown the modulating influence of memory load and response temporal constrains on the effects of implemental mindsets (Gollwitzer, 2012; Meiran et al., 2012), we examine the interaction between mindsets and type of task (aSRC vs. explicit task).

4. Finally, we intend to ascertain whether the combination of categories and mindsets affect evaluations in an additive way both for the indirect and the explicit tasks, that is, both for hedonic value and preference.

\section{Method}

\section{Participants}

Sixty-five volunteer undergraduate students (12 male) from the University of the Balearic Islands (UIB) (age: $M=21.55, S D=3.98)$ took part in the experiment in exchange for credits in the course. All participants reported normal or corrected-to-normal vision and provided written 
consent before the experiment. The experiment received approval by the Research Ethics Committee (CER) of the UIB and was conducted in accordance with the Declaration of Helsinki (2008).

\section{Materials}

We created 48 abstract grey patterns to minimize characteristics related to visual preferences such as semantic content, familiarity and affective valence (Leder et al., 2011). The images were designed with EazyDraw (Version 7; Dekorra Optics LLC, Poynnette, WI, USA). These images were sets of 4 stimuli based on patterns of points (Figure 1a, 1b). To obtain the symmetric sharp version of the stimulus 15 points were vertically distributed in 13 levels spaced equally apart. The first and the second point were at the same vertical level (V0), and the fourteenth and the fifteenth at the last level (V12). The horizontal axis values were randomized from 0 to 50, except for the first and last points, which remained at 0 . Subsequently, all 15 points were joined by segments, constituting half of the contour, which was duplicated and flipped onto the vertical axis. For the asymmetric sharp version, a new 13-point pattern was created following the aforementioned procedure, and then merged with the first pattern. When creating the asymmetric version, we controlled that the number of concavities and convexities were the same on both sides and occupied the same area as the symmetric version. When the number of concavities and convexities did not match, new values were randomly selected for the second pattern until the image had the appropriate number of concavities and convexities. Finally, to create the curved versions, we used the tool Transform Round in EazyDraw to transform a sharp-angled contour into a curved contour using a constant parameter. In each stimulus set, we equalized the area slightly enlarging or diminishing the stimulus. Image sizes were set at 321 x 463 pixels. In all, we obtained 12 stimuli for each combination of categories: symmetric-curved, symmetric-sharp, asymmetric-curved and asymmetric-sharp (Figure 1b). 
a

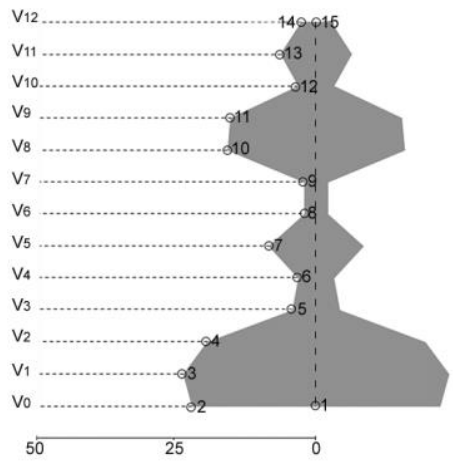

b
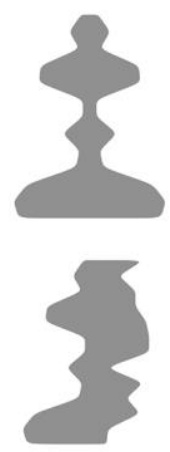

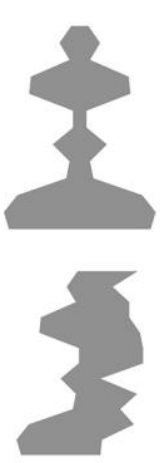

$c$
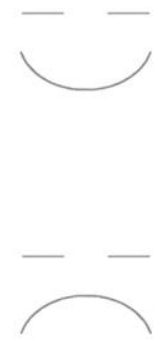

Figure 1. a. Pattern of 15 points used to design the stimuli. b. The four types of abstract patterns. c. Schematic facial expressions used as response cues: happy and sad.

Since some studies suggest that when responses acquire evaluative meaning SRC tasks achieve some of the benefits of single-categorization paradigm (Eder et al., 2015; Govan \& Williams, 2004), we framed responses using happy and sad schematic expressions as response keys (Figure 1c). The expressions consisted of two simple straight lines representing eyes, and a half ellipse, which was turned down, representing a sad mouth, or turned up, representing a happy mouth. We minimized the effect of curvature and symmetry of the eyes sketching them as simple lines. Images were resized at $120 \times 200$ pixels. These response keys were designed considering Salgado-Montejo et al. (2016)'s conclusions, according to which these simple lines represent specific affective states (happy and sad).

Participants carried out the experimental task using individual computers in isolated cabins with similar light conditions and with an approximate distance to the screen of $45 \mathrm{~cm}$. The task was designed with OpenSesame (3.1) software (Mathôt et al., 2012). Computers were equipped with Intel i5 processors and 21 -inch screens set at $1920 \times 1080$ pixels resolution and $60 \mathrm{~Hz}$. The stimuli measured $14.37 \mathrm{~cm}$ on the vertical axis and $10 \mathrm{~cm}$ on the horizontal axis. 


\section{Procedure}

For the indirect assessment of the hedonic value we designed a revised version of the aSRC task proposed by Eder et al. (2013). This variant, although closely related to the standard IAT, partly avoids some of its limitations, as explained in the introduction. Hence, we removed the classical block structure and dispensed with the label trials in order to reduce the method-specific variance (Mierke \& Klauer, 2003).

The aSRC task consisted of two main parts, one for each type of mindset. Intention-based instructions were used to activate either a symmetry mindset or a contour mindset, thus making participants to selectively attend to only one of the features. For each mindset, both an assumed compatibility block and an assumed incompatibility block were defined by means of the instructed task-set. Thus, each part of the administration consisted of one block for the expected compatible Task-set (Task-set 1, from now on) and another block for the expected incompatible one (Taskset 2, from now on) (see Figure 2a).

Participants received verbal instructions before the whole experimental session and written instructions before each part and before each task-set. Regarding the contour part, they were instructed that curved or sharp-angled shapes would be presented. In the Task-set 1 their task was to match the curved stimuli with the happy expression and the sharp-angled stimuli with the sad one, whereas in the Task-set 2 they had to match the curved stimuli with the sad expression and the sharp-angled stimuli with the happy one. As for the symmetry part, they were instructed that symmetric or asymmetric shapes would be presented. In the Task-set 1, they had to match the symmetric stimuli with the happy expression and the asymmetric stimuli with the sad one, whereas in the Task-set 2 they had to match the symmetric stimuli with the sad expression and the asymmetric stimuli with the happy one. In each part and task-set, participants were required to carry out the discrimination task as fast as possible. 
a Implicit task

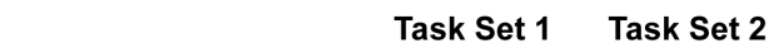

SYMMETRY MINDSET

Task Set 1 Task Set 2

b Explicit task

\section{SYMMETRY MINDSET | CONTOUR MINDSET}

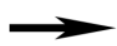

Time
4

$100 \mathrm{~ms}$

$500 \mathrm{~ms}$

\section{CONTOUR MINDSET}

Task Set 1 Task Set 2

Curved

Sharp-angled

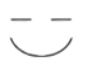

-

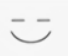

$100 \mathrm{~ms}$

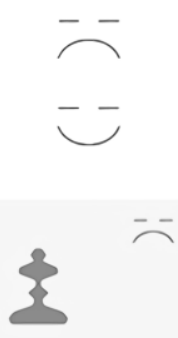

$2000 \mathrm{~ms}$ SYMMETRY MINDSET

.


Task-set. Part sequence was counterbalanced. Specifically, 33 participants carried out the symmetry part first and 32 participants carried out the contour part first. In every part, all participants first carried out the Task-set 1 and just after the Task-set 2. This fixed sequence was based on previous studies and a broad meta-analysis (Hofmann et al., 2005) that indicated that counterbalancing compatibility might artificially increase implicit-explicit correlations compared to a fixed sequence of compatibility and incompatibility blocks. Trials presentation was randomized. Completing the experiment took about 15 minutes.

After the aSRC task, participants carried out the explicit task with the same stimuli. According to the meta-analysis by Hofmann et al. (2005), the order of implicit and explicit measurement do not affect implicit-explicit correlations. In the explicit task, participants had to rate with a Likert scale from 1 ("I don't like it at all”) to 7 (“I like it a lot”) how much they liked each stimulus based on a contour mindset in one part and based on a symmetry mindset in the other

(Figure 2b). As in the case of the aSRC task, this mindset manipulation was induced by asking participants to base their ratings in the correspondent feature (contour or symmetry). There were 2 practice and 48 experimental trials in each part. The sequence of parts was counterbalanced, and trials presentation was randomized.

\section{Analysis}

In the aSRC task, we collected 12480 experimental trials and discarded the practice ones. As only correct responses were considered, 1189 incorrect trials were excluded from the analysis $(9.53 \%$ of total trials). We identified two participants with error rates above $30 \%$, who were dropped from the analysis (237 trials). Delayed (above $2000 \mathrm{~ms}$ ) and anticipated (300 ms) responses were excluded from the whole trial sample (204 trials, 1.85\%). After data cleaning, 10850 trials from 63 participants remained. 


\section{Results}

Analyses were conducted with SPSS 22.0.0 (SPSS Inc., Chicago, IL, USA) or R environment for statistical computing (R Core Team, 2018), using an alpha level of .05. Posthoc tests used Bonferroni correction. We calculated confidence intervals $(\mathrm{Cl})$ for effect sizes using an ad hoc script (http://daniellakens.blogspot.com.es/2014/06/calculating-confidenceintervals-for.html), ascertaining the obtained values with the "MBESS" package from the R statistical software (Kelley, 2007).

\section{aSRC task}

Following Eder et al. (2013), the analyses focused on participants' mean response time (RTs) -instead of on a $D$ score, as used to be the case for this kind of implicit tasks (Greenwald et al., 2003). This way, we examined the interactions between Task-set 1 and 2, and Mindset, Contour and Symmetry variables.

The sequence of parts was not significant, $F(1,62)=.323, p=.572, \mathrm{n}_{\mathrm{p}}^{2}=.005,90 \% \mathrm{Cl}$ $[0, .009]$. Thus, we conducted a four-factor mixed ANOVA on RT with Mindset (Contour vs. Symmetry), Task-set (1 vs. 2), Contour (Curved vs. Sharp-angled) and Symmetry (Symmetric vs. Asymmetric) as within-subject factors. All the results from the ANOVA are in Table 1. 
Table 1. Implicit task analysis. 2 (Mindset: Contour vs. Symmetry) x 2 (Task-set 1 vs. Task-set 2) x 2 (Contour: Curved vs. Sharp-angled) x 2 (Symmetry: Symmetrical vs. Asymmetrical) ANOVA on RTs.

\begin{tabular}{lcccc}
\hline \multicolumn{1}{c}{ Factor } & $\boldsymbol{F}$ & $\boldsymbol{p}$ & $\boldsymbol{\eta}^{2}$ & $\mathbf{9 0} \% \mathbf{C l}$ \\
\hline Mindset & .087 & .77 & .001 & {$[0, .05]$} \\
Task-set (Compatibility) & 43.9 & $<.001^{* * *}$ & .415 & {$[.26, .53]$} \\
Symmetry & 3.37 & .07 & .052 & {$[0, .16]$} \\
Contour & .30 & .59 & .005 & {$[0, .07]$} \\
Mindset x Compatibility & 10.17 & $.002^{* *}$ & .14 & {$[.03, .27]$} \\
Mindset x Symmetry & 4.64 & $.035^{*}$ & .06 & {$[0, .21]$} \\
Mindset x Contour & 2.56 & .11 & .04 & {$[0, .14]$} \\
Compatibility x Symmetry & .22 & .64 & .003 & {$[0, .06]$} \\
Compatibility x Contour & 8.2 & $.006 * *$ & .117 & {$[.02, .24]$} \\
Symmetry x Contour & 17.66 & $<.001 * * *$ & .22 & {$[.08, .36]$} \\
Mindset x Compatibility x Symmetry & .11 & .74 & .002 & {$[0, .05]$} \\
Mindset x Compatibility x Contour & .21 & .65 & .003 & {$[0, .061]$} \\
Mindset x Symmetry x Contour & 1.05 & .31 & .017 & {$[0, .1]$} \\
Compatibility x Symmetry x Contour & .25 & .62 & .004 & {$[0, .064]$} \\
Mindset x Compatibility x Symmetry x Contour & .21 & .07 & .05 & {$[0, .16]$} \\
\hline
\end{tabular}

Results yielded a significant main effect of Task-set. Participants performed faster in Task-set $1(M=965, S D=144)$ than in Task-set $2(M=1064, S D=180)$. Participants were faster either when pressing the happy-key to respond to curved or symmetric stimuli or the sad-key to respond to sharp-angled or asymmetric stimuli than when they responded either by pressing the happy-key to sharp-angled or asymmetric stimuli or the sad-key to curved or symmetric stimuli. 
This result supported Task-set 1 as the compatible condition between stimulus and response, and Task-set 2 as the incompatible condition. Therefore, from now on, we consider Task-set 1 as the compatible condition and Task-set 2 as the incompatible condition. All other main effects were nonsignificant.

Results showed four significant two-way interactions. Two of them involved affective Compatibility, which was directly related to the objective of the research. The other two significant interactions, Contour $x$ Symmetry and Mindset $x$ Symmetry, were related to processing time of specific kinds of stimuli.

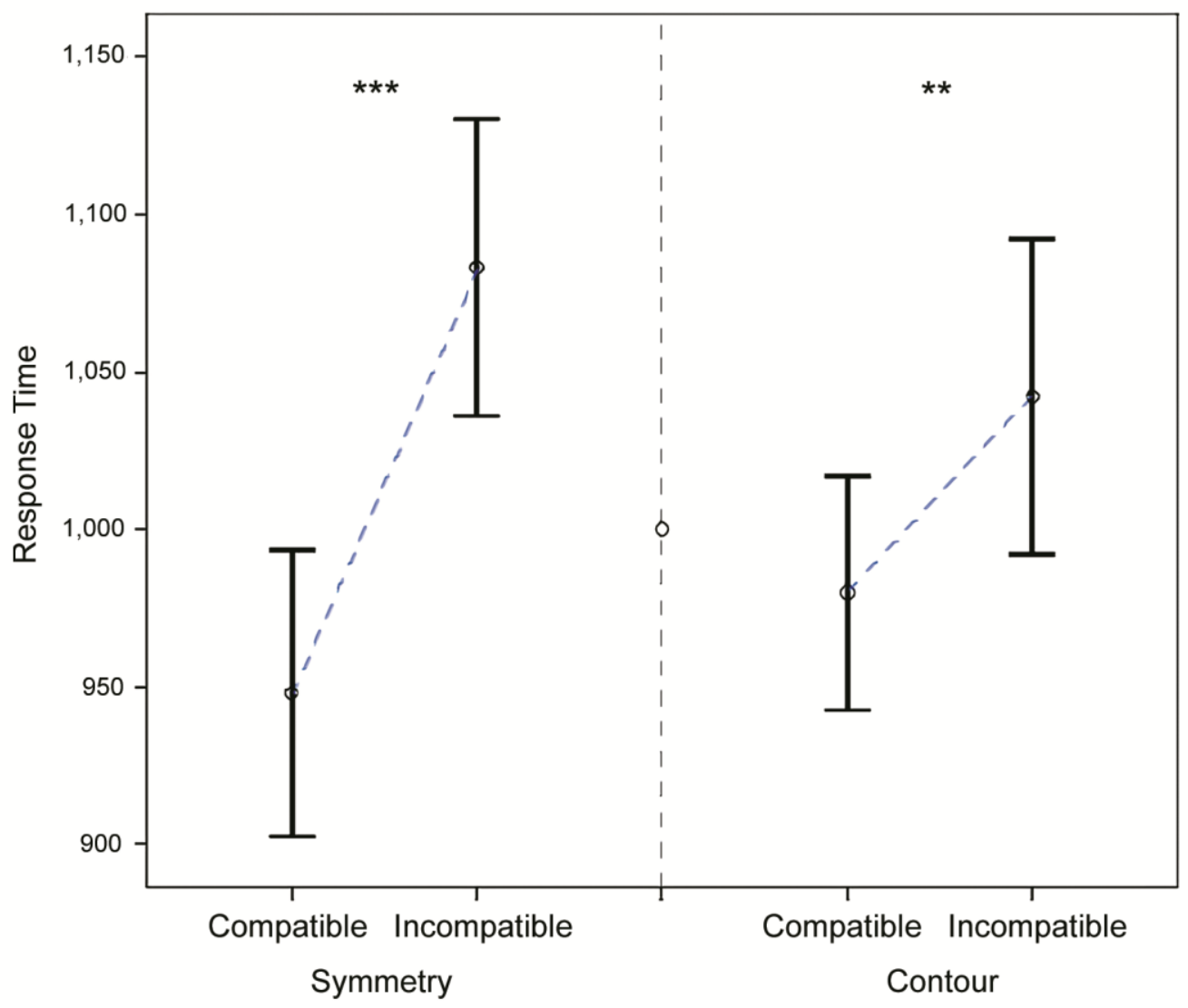

Figure 3. Mindset x Compatibility interaction. The difference between compatible and incompatible trials was higher in the symmetry mindset than in the contour mindset ${ }^{* \star *} p<$ $\left..001 ;{ }^{* *} p<.01\right)$. Error bars represent $95 \%$ confidence intervals. 
The significant interaction Mindset x Compatibility (Figure 3) shows that, although the effect of Compatibility was significant both in symmetry and contour mindsets, the effect size was higher in symmetry, $t(62)=7.522 ; p<.001 ; g=.726 ; 90 \% \mathrm{Cl}[.54, .926]$, than in contour, $t(62)=3.265 ; p=.002 ; g=.351 ; 90 \% \mathrm{Cl}[.168, .541]$. As the confidence intervals of the effect sizes do not overlap, we conclude that the symmetry mindset influenced the affective Compatibility measure more than the contour mindset. That is, symmetry made a larger contribution than curvature to the hedonic valuation.

Compatibility x Contour was also significant. Regarding our objectives, the interesting point of this interaction is that the difference between compatible and incompatible trials was higher with curved stimuli, $t(62)=7.029, p<.001, g=.677,90 \% \mathrm{Cl}[.505, .892]$, than with sharpangled stimuli, $t(62)=5.163, p<.001, g=.459,90 \% \mathrm{Cl}[.312, .652]$. As the two Cls slightly overlap, we cannot sustain that the affective compatibility effects are different in curved and sharpangled stimuli. However, as the different mindset seems to be crucial in this interaction, the triple interaction analysis between the factors clarified this point.

The Mindset x Compatibility x Contour interaction showed an effect size that could be interpreted as fairly close to a medium effect based on Cohen's criteria, $\eta_{p}^{2}=.052, \omega_{p}^{2}=.036$, $r=.229$ (Cohen, 1994; Open Science Collaboration, 2015). Additionally, this triple interaction clarified specific details about the previously explored Compatibility x Contour interaction. Figure 4 illustrates the underlying reason for the triple interaction effect. Sharp-angled stimuli in the contour mindset was the only case in which the difference between compatible and incompatible trials was nonsignificant, $t(62)=1.531, p=.131, g=.176,90 \% \mathrm{Cl}[.016, .382]$. When using curved stimuli, the difference was significant, $t(62)=4.385, p<.001, g=.49,90 \% \mathrm{Cl}[.294$, $.691]$. In the symmetry mindset, both symmetric, $t(62)=7.069, p<.001, g=.7,90 \% \mathrm{Cl}[.511, .904]$, and asymmetric stimuli, $t(62)=6.621, p<.001, g=.697,90 \% \mathrm{Cl}[.498, .908]$ showed significant differences between compatible and incompatible conditions. 


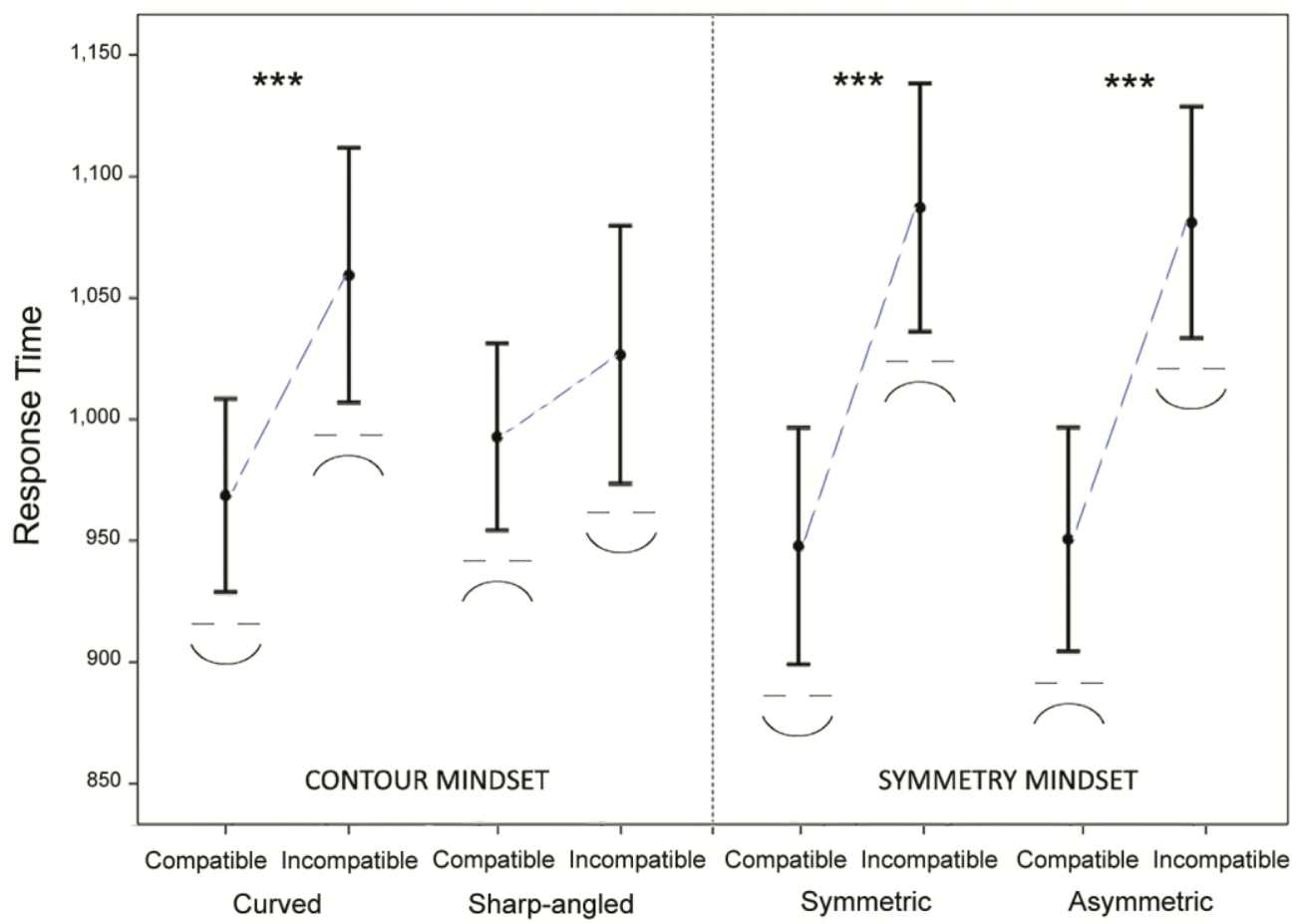

Figure 4. Mindset x Compatibility $x$ Contour interaction. All differences between compatible and incompatible trials were significant $\left({ }^{* *} p<.001\right)$, except with sharp-angled stimuli. Error bars represent $95 \%$ confidence intervals.

Contour x Symmetry was also significant. Participants were faster with curved than sharp-angled patterns in symmetric stimuli, $t(62)=2.79, p=.007, g=.14,90 \% \mathrm{Cl}[.058, .24]$, whereas they were faster with sharp-angled than curved patterns in asymmetric stimuli, $t(62)=2.38, p=.02, g=.12,90 \% \mathrm{Cl}[.035, .207]$ (Figure 5). RT was lower when the valences of the two visual properties were the same (positive: curved and symmetric; or negative: sharp-angled and asymmetric) than when they were different (curved and asymmetric, or sharp-angled and symmetric), regardless of mindset and response compatibility with the stimuli. In other words, the coherence of affective valences facilitated RT. 
Running head: PREFERENCE FOR SYMMETRY AND CURVATURE

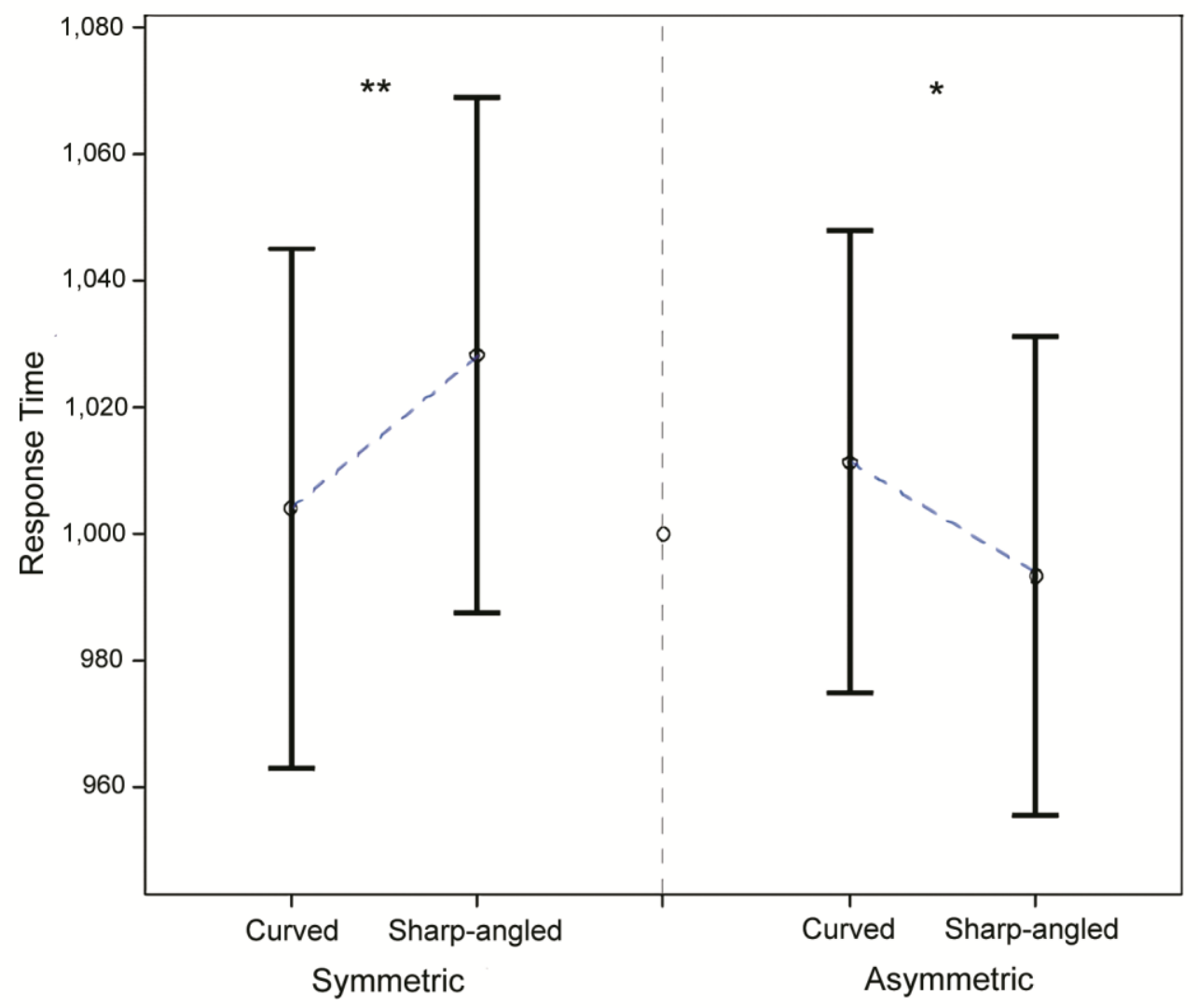

Figure 5. Contour x Symmetry features interaction $\left({ }^{* *} p<.01 ;{ }^{*} p<.05\right)$. Error bars represent 95\% confidence intervals.

Finally, Mindset x Symmetry was also significant. Participants responded faster to asymmetric than to symmetric stimuli when mindset was contour, $t(62)=3.022, p=.004, \eta_{p}^{2}=.128$, but not when it was symmetry, $t(62)=.172, p=.864, \eta_{p}^{2}<.001$ (Figure 6). 


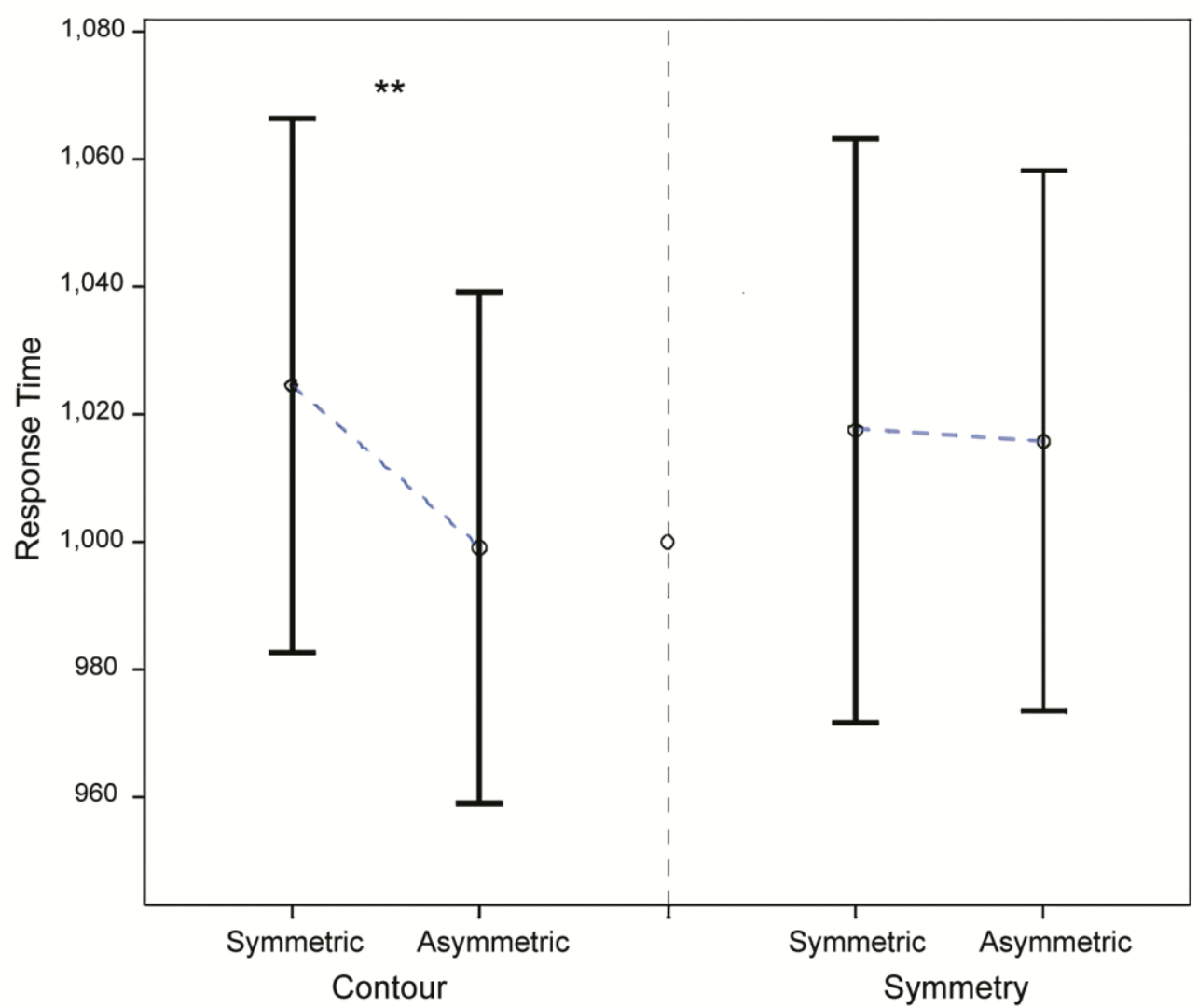

Figure 6. Mindset x Symmetry feature interaction $\left.{ }^{* *} p<.01\right)$. Error bars represent $95 \%$ confidence intervals.

\section{Explicit task}

We calculated a general explicit value from the average of the two explicit parts (contour and symmetry mindsets). The four kinds of stimuli showed significantly different general explicit values (Figure 7a). The most liked stimuli were the symmetric-curved ones. Their values were significantly higher than those of the symmetric-sharp patterns, $t(62)=7.88, p<.001, g=.965,90 \%$ $\mathrm{Cl}[.724,1.223]$. The latter obtained significantly higher values than the asymmetric-curved patterns, $t(62)=8.35, p<.001, g=1.419,90 \% \mathrm{Cl}[1.078,1.785]$. Lastly, the asymmetric-curved patterns obtained also significantly higher values than the least liked patterns, the asymmetricsharp ones, $t(629=7.3, p<.001, g=1.037,90 \% \mathrm{Cl}[.768,1.336]$. All the effect sizes were large. 
As this explicit averaged value could be influenced by both mindsets, we ran again the explicit task without any specific mindset with 70 participants who had not performed the main experiment (Mean age=20.9, 15 men). Explicit values were calculated from a single block without the mindset manipulation. Figure $7 \mathrm{~b}$ shows that results (averages and standard deviations) were almost the same as the ones in the Figure 7a. They endorse using the general averaged value from the two explicit tasks.

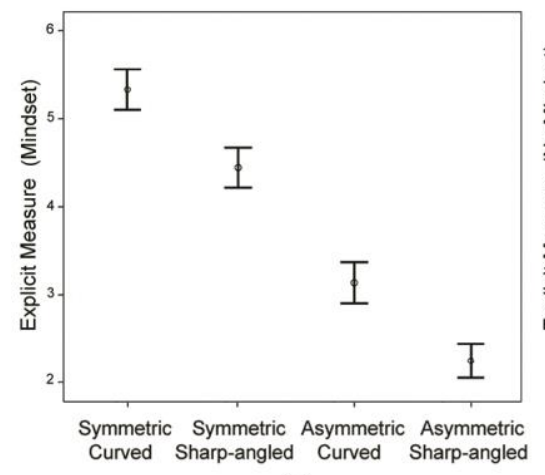

(a)

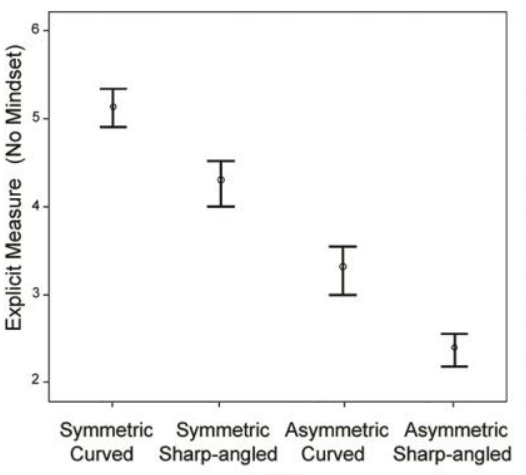

(b)

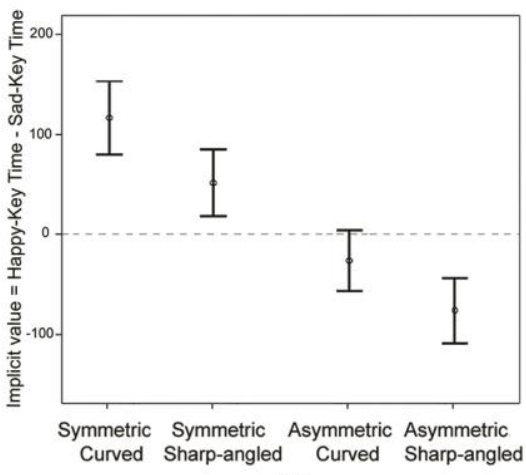

(c)

Figure 7. Explicit and implicit measures. (a). Explicit liking ratings of the four types of stimuli (all p's $<.001$ ). These values were calculated from the average of the two mindsets (contour and symmetry). (b). Supplementary explicit liking ratings calculated in another explicit task without mindsets. Both explicit liking results show highly similar patterns. (c). RTs differences between happy-key and sad-key to each type of stimuli. A positive value implies a correspondence with happy-key, whereas a negative value implies a correspondence with sad-key (all p's <.05). Error bars represent 95\% confidence intervals.

With regard to the correlation between the aSRC results and the explicit measure, it is worth mentioning first that although SCR tasks are commonly claimed to capture implicit evaluations (Gawronski et al., 2020), the prevailing confusion regarding the implicitness construct (Corneille \& Hütter, 2020) makes it advisable to specify that the term implicit refers here to indirect 
measures and largely automatic outcomes that capture efficient, autonomous, and probably unaware valuations -the valence of the attended stimulus is always irrelevant for response selection-, with no further conceptual assumptions.

In order to compare explicit and implicit measures, we calculated a general implicit value. We subtracted RT for the sad-key from RT for the happy-key in every kind of stimulus. This way, we obtained a value directly related to the happy-key RT and inversely related to the sad-key RT. As Figure 7c shows, the tendency of the implicit values was quite similar to the explicit values in 7a and $7 \mathrm{~b}$. The implicit values with symmetric-curved stimuli were significantly higher than the values with symmetric-sharp ones, $t(62)=2.69, p=.009, g=.463,90 \% \mathrm{Cl}[.172$, .763]. The values of the latter were also significantly higher than the values with asymmetriccurved stimuli, $t(62)=2.97, p=.004, g=.603,90 \% \mathrm{Cl}[0.258,0.958]$. Finally, the difference between the values of these last stimuli and those of the asymmetric-sharp ones was also significant according to the Bonferroni correction, $t(63)=2.23, p=.03, g=.392,90 \% \mathrm{Cl}[.096$, .695].

As we had an explicit measure for every mindset, we performed a similar analysis for each one. The most relevant change was that the difference between symmetric-sharp and asymmetric-curved stimuli decreased in contour mindset (Figure 8a) becoming nonsignificant, $t(63)=1.9, p=.063, g=.361,90 \% \mathrm{Cl}[.042, .685]$, and it increased significantly in symmetry mindset, $t(63)=11.21, p<.001, g=2.094,90 \% \mathrm{Cl}[1.672,2.554]$. 

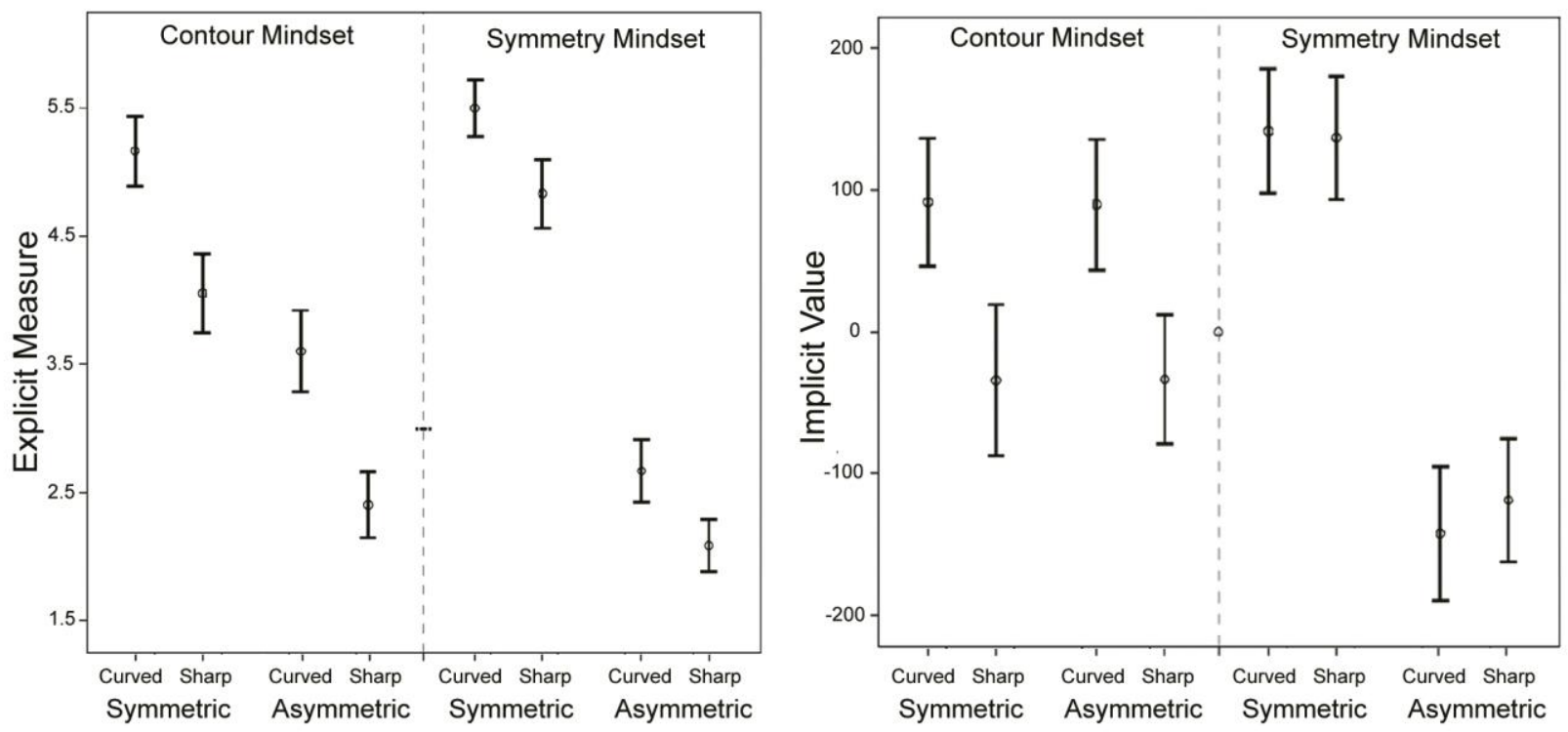

Figure 8. (a). The results of the explicit measure in contour and symmetry mindsets. Within each mindset, all differences were significant, except for the symmetric/sharp and asymmetric/curved stimuli in the contour mindset $(p=.063)$. (b). The results of the implicit aSRC measure in contour and symmetry mindsets. Curved and symmetric stimuli showed higher implicit values in the contour and symmetry mindset respectively. Error bars represent $95 \%$ confidence intervals.

Regarding the implicit value, the big picture changed considerably (Figure 8b). This was due to symmetric-sharp and asymmetric-curved stimuli. Symmetric-sharp stimuli reached similar values to the asymmetric-sharp ones when mindset was contour, and similar values to the symmetric-curved ones when mindset was symmetry. On the contrary, asymmetric-curved stimuli reached similar values to symmetric-curved ones when mindset was contour and similar to asymmetric-sharp ones when mindset was symmetry. This showed that the implicit value depends quite a lot on mindset.

Finally, we calculated participants' correlations between explicit and implicit measures. As Table 2 shows, we found no significant results. Stimulus' correlation between the two measures was also nonsignificant, $r(48)=.204, p=.165$. 
Running head: PREFERENCE FOR SYMMETRY AND CURVATURE

Table 2. Correlations between explicit and implicit measures.

\begin{tabular}{|c|c|c|}
\hline & $\begin{array}{c}\text { Pearson } \\
\text { correlation }\end{array}$ & Significance $(p)$ \\
\hline \multicolumn{3}{|c|}{ General } \\
\hline Symmetrical-curved & .118 & .359 \\
\hline Symmetrical-sharp & -.172 & .177 \\
\hline Asymmetrical-curved & -.102 & .425 \\
\hline Asymmetrical-sharp & .098 & .447 \\
\hline \multicolumn{3}{|c|}{ Contour mindset } \\
\hline Symmetrical-curved & .127 & .32 \\
\hline Symmetrical-sharp & -.011 & .931 \\
\hline Asymmetrical-curved & .078 & .545 \\
\hline Asymmetrical-sharp & -.071 & .58 \\
\hline Curved & .122 & .342 \\
\hline Sharp-angled & .051 & .691 \\
\hline \multicolumn{3}{|c|}{ Symmetry Mindset } \\
\hline Symmetrical-curved & .099 & .439 \\
\hline Symmetrical-sharp & .027 & .834 \\
\hline Asymmetrical-curved & .161 & .209 \\
\hline Asymmetrical-sharp & .101 & .432 \\
\hline Curved & .097 & .449 \\
\hline Sharp-angled & -.148 & .248 \\
\hline
\end{tabular}

\section{Discussion}

\section{Preference and visual features interaction}

Our main goal was to test, from a nomothetic approach, the effects of the interaction between symmetry and curvature on the automatic hedonic valuation through a revised aSRC task. We defined symmetry and contour as different mindsets to carry out the tasks. Participants focused on one of two features in different parts. We used four types of stimuli that combined 
the two features. We also designed an explicit liking task with the same mindsets and stimuli, to compare implicit and explicit measures.

In the aSRC task, when symmetric or curved stimuli were associated with a happy face and asymmetric or sharp-angled stimuli were associated with a sad face, the trials were considered compatible. When symmetric or curved stimuli were associated with a sad face and asymmetric or sharp-angled with a happy face, the trials were considered incompatible. Participants responded faster to compatible trials than to incompatible trials both in symmetry and contour mindsets. This finding implicitly reveals a positive valence and a hedonic tone for symmetry and curvature without asking participants to report their judgments overtly. This hedonic component could be interpreted as preference. Preference for symmetry has been tested using other similar implicit paradigms with dot patterns (Makin et al., 2012) and configurations of black and white squares and triangles (e.g., Weichselbaum et al., 2018). Similarly, Palumbo et al. (2015) showed positive valence for curvature using curved and angular abstract polygons in an IAT and a mannikin task.

When comparing confidence intervals of effect sizes, symmetry showed a large effect and curvature a medium effect. It suggests that symmetry's contribution to the hedonic tone is stronger than curvature's contribution. However, we cannot reject that this advantage of symmetry might be due to the kind of stimuli we used. In our stimuli, symmetry might stand out more than curvature, but it needs to be tested.

The triple interaction between symmetry, contour, and compatibility was not significant. Hence, we conclude that the hedonic tone in symmetry does not depend on the kind of contour, and the hedonic tone in curvature does not depend on whether or not the pattern is symmetric. Furthermore, these two visual features show a cumulative effect, as indicated in our implicit and explicit results. This is consistent with the hypothesis about the expected interaction between visual features if they had the same affective valence. The stimuli with the most positive valence were the symmetric-curved ones and the least were the asymmetric-sharp stimuli. In the middle, 
the symmetric-sharp stimuli had more positive valence than the asymmetric-curved ones. This fact emphasizes the symmetry effect over the curvature effect.

In the aSRC task, what we interpret as hedonic valuation for symmetry and curvature only appeared clearly with the corresponding mindset, either symmetry or contour. Furthermore, the non-mindset condition did not diminish or increment the hedonic effect. Therefore, we can conclude that, according to our results, symmetry and curvature play no role in an aSRC task when they are ignored. These results are congruent with the evidence that implemental mindsets entail filtering of information, thus favouring the focus on the task at hand while decreasing the processing of irrelevant information (Fujita et al., 2007; Gollwitzer, 2012). Other results suggest that this increased selectivity may be due, at least in part, to a greater focusing of visual attention (Büttner et al., 2014). In addition, this evidence is in line with previous studies according to which the compatibility effect is greater when stimulus features are task-relevant than when they do not need to be processed to properly perform the task (Kornblum \& Lee, 1995; Suchotzki et al., 2013).

On the other hand, contributions of symmetric and asymmetric stimuli to a most positive valence for symmetry were quite similar when the mindset was symmetry. However, when the mindset was contour, the contribution of sharp-angled stimuli was non-significant, and the most valence for curvature was mainly only caused by curved stimuli. Concerning the debate of whether the curvature effect is based on rejection of sharpness (Bar \& Neta, 2006, 2007) or on a pure inclination for curvature (Gómez-Puerto et al., 2016; Palumbo et al., 2015), our findings indicated that preference for curvature is basically due to inclination for curved patterns, and the rejection of sharp-angled patterns is not substantial. However, we cannot rule out an implicit process based on sharpness rejection when people do not focus on the visual properties of the stimuli. Our finding comes from a task in which participants were clearly focused on contour and, in the symmetry mindset, the focus on symmetry might cancel a hypothesized implicit process of sharpness rejection 
We also obtained some striking findings about the RT related to specific stimulus properties and conditions. Participants responded equally fast to symmetric and asymmetric stimuli when they had to decide whether or not the stimuli were symmetric. However, they responded faster to asymmetric than to symmetric stimuli when they had to decide whether they were curved or sharp-angled. Conversely, some researchers suggested a temporal advantage to detect symmetric versus asymmetric patterns (Bornstein et al., 1981; Reber, 2002). This is consistent with the idea that perceptual fluency guides preference formation and even preference. The fluency hypothesis states that high fluency elicits positive affect and subjective beauty appraisals (Reber et al., 2004). Some studies showed that participants were quicker to respond to reflection symmetry than to random patterns (Bruce \& Morgan, 1975; Makin et al., 2012). Nonetheless, participants were faster to detect asymmetric patterns than symmetric patterns in Royer's work (Royer, 1981). Also, Jacobsen and Höfel (2003) and Friedenberg (2018) showed that participants responded slower to reflected symmetric shapes than to asymmetric shapes on a rating scale task about beauty. Thus, our results about the symmetry assessment do not support the fluency hypothesis. Moreover, neither do our results about the curvature effect support the fluent hypothesis. There are different explanations for the discrepancy in results, but this was not the main objective of our study.

Our results suggested that symmetry and curvature are associated to positive (happy) schematic facial expressions, and asymmetry and sharpness are associated with negative (sad) schematic facial expressions. They also showed that participants were faster when both valences coincided -positive or negative- than when they did not coincide. The longer RTs when stimulus valences did not match (symmetric-sharp or asymmetric-curved) might be associated with the need to solve the dual-valence representation associated with surprised expressions that predict either positive or negative outcomes (Neta \& Whalen, 2010). Another perspective to explain these results stems from the idea of interference when the level of the other property -contour or symmetry-does not coincide in valence with the one that the 
participant is responding to. Anyway, the correspondence of the faster response when the two affective positive dimensions and the highest liking in this kind of stimuli could be interpreted as a further proof of the correspondence between implicit positive valence and explicit preference.

\section{Implicit hedonic tone and explicit preference}

When comparing the four kinds of stimuli, the general pattern was quite similar in the implicit aSRC and the explicit task. However, this pattern changed when we included the mindset factor. Moreover, all correlations between implicit and explicit measures were nonsignificant.

Several authors reported low correlations between implicit and explicit measures (e.g., Hofmann et al., 2005). Hofmann et al. (2005) indicated that correlations increased as a function of (a) increasing spontaneity of explicit measures, and (b) increasing conceptual correspondence between both measures. It is consistent with the assumption that implicit measures primarily reflect automatic associations, whereas explicit measures depend on the effortful retrieval of information from memory. Explicit measures might reflect automatic associations to a greater extent when participants do not have the possibility to retrieve additional information from memory. In our case, if the presentation time had been shorter in the explicit measures, the associations would have been more automatic and, consequently, the correlations could have been higher. For example, Corradi et al. (2018) showed that explicit preference for curvature changed depending on presentation time.

Regarding the possibility of the lack of conceptual correspondence between the two measures, the happy/sad dimension might not be the most precise approach to transfer the feeling produced by curved and sharp-angled contours, respectively. In this regard, other dimensions such as happy/angry, pleased/unpleased, or satisfied/unsatisfied need to be tested because they might show higher correspondence between the two measures.

Nosek (2005) and Nosek and Smyth (2007) indicated that implicit and explicit evaluations appear to be distinct constructs, with a relationship moderated by intrapersonal and 
interpersonal evaluative features. However, distinct implicit and explicit constructs do not rule out the possibility that the two constructs derive from common evaluative content (Nosek \& Smyth, 2007). Nosek (2005) suggested that the relationship between implicit and explicit evaluations is mainly moderated by (a) the effortful presentation for personal or social purposes (self-presentation), (b) the vigour of the evaluations (strength), (c) the extent to which evaluations are represented with a simple, bipolar structure (dimensionality), and (d) the extent to which one's evaluation is perceived as distinct from normative responses (distinctiveness).

Following Nosek (2005) suggestions, three possibilities might explain the lack of correspondence between our measures. One explanation might be that they are not strong evaluations. Preference for symmetry and curvature, using abstract patterns, are not personally important, highly familiar, frequently thought about, stable, extreme, and unambivalent, as Nosek (2005) defined the strength factor. In this regard, meaningful stimuli might elicit stronger decisions and, hence, implicit and explicit correlations could be significant. According to the selfpresentation factor, another possibility is that explicit values can be deliberately increased because of the particular context, while implicit values may not be altered. Thus, we found that the effect sizes of the explicit measure were higher than those from the implicit measure. Finally, it is possible that preference for symmetry and curvature are not bipolar continuums (dimensionality). For instance, liking symmetry stimuli does not imply disliking asymmetry. Bipolar evaluations are automatically activated more readily and consistently than evaluations not conforming to that structure (Nosek, 2005).

\section{Limitations}

The analyses were employed to derive group comparisons, that is, it is a nomothetic study. However, some studies have shown substantial individual differences on preference for symmetry (Jacobsen \& Höfel, 2002) and preference for curvature (Corradi et al., 2019).

Therefore, it is necessary to complement our study with an idiographic approach. Further, we used a specific kind of stimuli, that is, meaningless patterns. Therefore, our approach can be 
further developed using other kind of stimuli, in order to support the evidenced contribution of symmetry and curvature to preference.

\section{Conclusion}

We explored the interaction between two visual features that shape initial visual preference, using implicit and explicit measures with two mindsets, symmetry and contour. We found an implicit association of curvature and symmetry with positive hedonic tone. Symmetry and curvature showed cumulative effects on preference in the explicit task and positive valence or hedonic tone in the implicit task. Moreover, we determined that the hedonic tone for curvature does not depend on symmetry, and the hedonic tone for symmetry does not depend on the kind of contour. Symmetry showed a larger effect than curvature on positive valence and preference. Our results also suggest that the curvature effect is mainly caused by the inclination for curved stimuli and not by the rejection of sharp-angled stimuli. Lastly, we did not find any correlation between explicit and implicit measures, supporting Nosek's (2005) suggestion that they might be distinct constructs using different processes and representations. Altogether, the design of implicit/explicit methods and the use of mindset tasks provides a constructive and flexible approach to study how stimulus features interact.

\section{Acknowledgments}

The authors thank Marcos Nadal for helpful comments on a previous version of the paper.

\section{Funding}

This research was funded by the project <PSI2016-77327-P> (MINECO/AEI/ERDF, EU) granted by the Ministerio de Ciencia, Innovación y Universidades, the Agencia Estatal de Investigación (AEI) and the European Regional Development Funds (ERDF). E.G.C. acknowledges the predoctoral contract FPU18/00365 granted by the Ministerio de Ciencia, Innovación y Universidades. 


\section{Declaration of Conflicting Interests}

The Authors declare that there is no conflict of interest.

\section{Data Accessibility Statement}

The dataset generated and analysed during the current study is available on the Open Science Framework: $\underline{\text { https://osf.io/kh4t3/ }}$

\section{References}

Armor, D. A., \& Taylor, S. E. (2003). The effects of mindset on behavior: Self-regulation in deliberative and implemental frames of mind. Personality and Social Psychology Bulletin, 29(1), 86-95. https://doi.org/10.1177/0146167202238374

Bar, M., \& Neta, M. (2006). Humans Prefer Curved Visual Objects. Psychological Science, 17(8), 645-648. https://doi.org/10.1111/j.1467-9280.2006.01759.x

Bar, M., \& Neta, M. (2007). Visual elements of subjective preference modulate amygdala activation. Neuropsychologia, 45(10), 2191-2200. https://doi.org/10.1016/j.neuropsychologia.2007.03.008

Becker, S., Bräscher, A. K., Bannister, S., Bensafi, M., Calma-Birling, D., Chan, R. C. K., Eerola, T., Ellingsen, D. M., Ferdenzi, C., Hanson, J. L., Joffily, M., Lidhar, N. K., Lowe, L. J., Martin, L. J., Musser, E. D., Noll-Hussong, M., Olino, T. M., Pintos Lobo, R., \& Wang, Y. (2019). The role of hedonics in the Human Affectome. In Neuroscience and Biobehavioral Reviews (Vol. 102, pp. 221-241). Elsevier Ltd. https://doi.org/10.1016/j.neubiorev.2019.05.003

Bertamini, M., Makin, A., \& Rampone, G. (2013). Implicit association of symmetry with positive valence, high arousal and simplicity. I-Perception, 4, 317-327. https://doi.org/10.1068/i0601jw

Birkhoff, G. D. (1932). Aesthetic measure (M. Cambridge (ed.)). Harvard University Press. Bornstein, M. H., Ferdinandsen, K., \& Gross, C. G. (1981). Perception of symmetry in infancy. 
Developmental Psychology, 17(1), 82-86. https://doi.org/10.1037/0012-1649.17.1.82

Bruce, V. G., \& Morgan, M. J. (1975). Violations of Symmetry and Repetition in Visual Patterns. Perception, 4(3), 239-249. https://doi.org/10.1068/p040239

Büttner, O. B., Wieber, F., Schulz, A. M., Bayer, U. C., Florack, A., \& Gollwitzer, P. M. (2014). Visual Attention and Goal Pursuit: Deliberative and Implemental Mindsets Affect Breadth of Attention. Personality and Social Psychology Bulletin, 4O(10), 1248-1259. https://doi.org/10.1177/0146167214539707

Carbon, C.-C., Mchedlidze, T., Raab, M. H., \& Wächter, H. (2018). The Power of Shape: How Shape of Node-Link Diagrams Impacts Aesthetic Appreciation and Triggers Interest. IPerception, 9(5), 204166951879685. https://doi.org/10.1177/2041669518796851

Che, J., Sun, X., Gallardo, V., \& Nadal, M. (2018). Cross-cultural empirical aesthetics. In Progress in Brain Research (Vol. 237, pp. 77-103). Elsevier B.V. https://doi.org/10.1016/bs.pbr.2018.03.002

Cohen-Kdoshay, O., \& Meiran, N. (2007). The representation of instructions in working memory leads to autonomous response activation: Evidence from the first trials in the flanker paradigm. Quarterly Journal of Experimental Psychology, 60(8), 1140-1154. https://doi.org/10.1080/17470210600896674

Cohen, J. D. (1994). The earth is round (p<.05). American Psychologist, 49, 997-1003.

Corneille, O., \& Hütter, M. (2020). Implicit? What Do You Mean? A Comprehensive Review of the Delusive Implicitness Construct in Attitude Research. Personality and Social Psychology Review, 24(3), 212-232. https://doi.org/10.1177/1088868320911325

Corradi, G., Belman, M., Currò, T., Chuquichambi, E. G., Rey, C., \& Nadal, M. (2019). Aesthetic sensitivity to curvature in real objects and abstract designs. Acta Psychologica, 197, 124130. https://doi.org/10.1016/j.actpsy.2019.05.012

Corradi, G., Rosselló-Mir, J., Vañó, J., Chuquichambi, E., Bertamini, M., \& Munar, E. (2018). The effects of presentation time on preference for curvature of real objects and 
meaningless novel patterns. British Journal of Psychology, 111, 630-658. https://doi.org/10.1111/bjop.12367

De Houwer, J. (1998). The Semantic Simon Effect. The Quarterly Journal of Experimental Psychology Section A, 51(3), 683-688. https://doi.org/10.1080/713755778

De Houwer, J., \& Eelen, P. (1998). An Affective Variant of the Simon Paradigm. Cognition and Emotion, 12(1), 45-62. https://doi.org/10.1080/026999398379772

De Houwer, J., Geldof, T., \& De Bruycker, E. (2005). The Implicit Association Test as a General Measure of Similarity. Canadian Journal of Experimental Psychology/Revue Canadienne de Psychologie Expérimentale, 59(4), 228-239. https://doi.org/10.1037/h0087478

Dongen, N. N. N. van, \& Zijlmans, J. (2017). The Science of Art: The Universality of the Law of Contrast. The American Journal of Psychology, 130(3), 283-294. https://doi.org/10.5406/amerjpsyc.130.3.0283

Eder, A. B., \& Rothermund, K. (2008). When Do Motor Behaviors (Mis)Match Affective Stimuli? An Evaluative Coding View of Approach and Avoidance Reactions. Journal of Experimental Psychology: General, 137(2), 262-281. https://doi.org/10.1037/0096-3445.137.2.262

Eder, A. B., Rothermund, K., \& De Houwer, J. (2013). Affective compatibility between stimuli and response goals: A primer for a new implicit measure of attitudes. PLOS ONE, 8(11). https://doi.org/10.1371/journal.pone.0079210

Eder, A. B., Rothermund, K., De Houwer, J., \& Hommel, B. (2015). Directive and incentive functions of affective action consequences: an ideomotor approach. Psychological Research, 79(4), 630-649. https://doi.org/10.1007/s00426-014-0590-4

Eisenman, R. (1967). Complexity-simplicity: I. Preference for symmetry and rejection of complexity. Psychonomic Science, 8(4), 169-170. https://doi.org/10.3758/BF03331603

Eisenman, R., \& Gellens, H. K. (1968). Preferences for complexity-simplicity and symmetryasymmetry. Perceptual and Motor Skills, 26(3), 888-890.

https://doi.org/10.2466/pms.1968.26.3.888 
Eysenck, H. J. (1941). The empirical determination of an aesthetic formula. Psychological Review, 48(1), 83-92. https://doi.org/10.1037/h0062483

Eysenck, H. J. (1968). An experimental study of aesthetic preference for polygonal figures. Journal of General Psychology, 79(1), 3-17. https://doi.org/10.1080/00221309.1968.9710447

Fitts, P. M., \& Deininger, R. L. (1954). S-R compatibility: Correspondence among paired elements within stimulus and response codes. Journal of Experimental Psychology, 48(6), 483-492. https://doi.org/10.1037/h0054967

Friedenberg, J. (2018). Perceived Beauty of Elongated Symmetric Shapes : Is More Better? Psychology of Aesthetics, Creativity, and the Arts, 12(2), 157-165. https://doi.org/10.1037/aca0000142

Fu, K., Zhang, Y., \& Lin, X. (2019). The Automatic Evaluation of Regularity and Semantic Decodability in Wallpaper Decorative Patterns. Perception, 48(8), 731-751. https://doi.org/10.1177/0301006619862142

Fujita, K., Gollwitzer, P. M., \& Oettingen, G. (2007). Mindsets and pre-conscious openmindedness to incidental information. Journal of Experimental Social Psychology, 43(1), 48-61. https://doi.org/10.1016/j.jesp.2005.12.004

Gawronski, B., De Houwer, J., \& Sherman, J. W. (2020). Twenty-Five Years of Research Using Implicit Measures. Social Cognition, 38(Supplement), s1-s25. https://doi.org/10.1521/soco.2020.38.supp.s1

Gollwitzer, P. M. (2012). Mindset Theory of Action Phases. In P. A. Lange (Ed.), Handbook of theories of social psychology (pp. 526-545). Los Angeles: Sage.

Gollwitzer, P. M., \& Bayer, U. (1999). Deliberative versus implemental mindsets in the control of action. In S. Chaiken \& Y. Trope (Eds.), Dual-process theories in social psychology (pp. 403-422). New York: Guilford Press.

Gómez-Puerto, G., Munar, E., \& Nadal, M. (2016). Preference for Curvature: A Historical and 
Conceptual Framework. Frontiers in Human Neuroscience, 9, 712. https://doi.org/10.3389/fnhum.2015.00712

Gómez-Puerto, G., Rosselló, J., Corradi, G., Acedo-Carmona, C., Munar, E., \& Nadal, M. (2017). Preference for Curved Contours Across Cultures. Psychology of Aesthetics, Creativity, and the Arts, 12(4), 432-439. https://doi.org/10.1037/aca0000135

Govan, C. L., \& Williams, K. D. (2004). Changing the affective valence of the stimulus items influences the IAT by re-defining the category labels. Journal of Experimental Social Psychology, 40(3), 357-365. https://doi.org/10.1016/j.jesp.2003.07.002

Graham, D., Schwarz, B., Chatterjee, A., \& Leder, H. (2016). Preference for luminance histogram regularities in natural scenes. Vision Research, 120, 11-21. https://doi.org/10.1016/j.visres.2015.03.018

Greenwald, A. G., Mcghee, D. E., \& Schwartz, J. L. K. (1998). Measuring Individual Differences in Implicit Cognition: The Implicit Association Test. Journal of Personality and Social Psychology, 74(6), 1464-1480. https://doi.org/10.1037/0022-3514.74.6.1464

Greenwald, A. G., Nosek, Brian, A., \& Banaji, M. R. (2003). Understanding and Using the Implicit Association Test: I. An Improved Scoring Algorithm. Attitudes and Social Cognition, 85(2), 197-216. https://doi.org/10.1037/0022-3514.85.2.197

Güçlütürk, Y., Jacobs, R. H. A. H., \& Lier, R. van. (2016). Liking versus Complexity: Decomposing the Inverted U-curve. Frontiers in Human Neuroscience, 10, 1-11. https://doi.org/10.3389/fnhum.2016.00112

Henderson, M. D., de Liver, Y., \& Gollwitzer, P. M. (2008). The Effects of an Implemental MindSet on Attitude Strength. Journal of Personality and Social Psychology, 94(3), 396-411. https://doi.org/10.1037/0022-3514.94.3.396

Höfel, L., \& Jacobsen, T. (2007a). Electrophysiological indices of processing symmetry and aesthetics: A result of judgment categorization or judgment report? Journal of Psychophysiology, 21(1), 9-21. https://doi.org/10.1027/0269-8803.21.1.9 
Höfel, L., \& Jacobsen, T. (2007b). Electrophysiological indices of processing aesthetics: Spontaneous or intentional processes? International Journal of Psychophysiology, 65(1), 20-31. https://doi.org/10.1016/j.ijpsycho.2007.02.007

Hofmann, W., Gawronski, B., Gschwendner, T., Le, H., \& Schmitt, M. (2005, October). A metaanalysis on the correlation between the Implicit Association Test and explicit self-report measures. In Personality and Social Psychology Bulletin, 31(10), 1369-1385. https://doi.org/10.1177/0146167205275613

Huang, Y., Lyu, J., Xue, X., \& Peng, K. (2020). Cognitive basis for the development of aesthetic preference: Findings from symmetry preference. PLOS ONE, 15(10), e0239973. https://doi.org/10.1371/journal.pone.0239973

Hübner, R., \& Fillinger, M. G. (2016). Comparison of Objective Measures for Predicting Perceptual Balance and Visual Aesthetic Preference. Frontiers in Psychology, 7, 1-15. https://doi.org/10.3389/fpsyg.2016.00335

Jacobsen, T., \& Höfel, L. (2002). Aesthetic Judgments of Novel Graphic Patterns: Analyses of Individual Judgments. Perceptual and Motor Skills, 95(3), 755-766. https://doi.org/10.2466/pms.2002.95.3.755

Jacobsen, T., \& Höfel, L. (2003). Descriptive and evaluative judgment processes: Behavioral and electrophysiological indices of processing symmetry and aesthetics. Cognitive, Affective, \& Behavioral Neuroscience, 3(4), 289-299. https://doi.org/10.3758/CABN.3.4.289

Kelley, K. (2007). Confidence Intervals for Standardized Effect Sizes: Theory, Application, and Implementation. Journal of Statistical Software, 20(8), 1-24. https://www3.nd.edu/ kkelley/publications/articles/Kelley_JSS_2007.pdf

Kornblum, S., \& Lee, J. W. (1995). Stimulus-Response Compatibility With Relevant and Irrelevant Stimulus Dimensions That Do and Do Not Overlap With the Response. Journal of Experimental Psychology: Human Perception and Performance, 21(4), 855-875. 
https://doi.org/10.1037/0096-1523.21.4.855

Leder, H., \& Nadal, M. (2014). Ten years of a model of aesthetic appreciation and aesthetic judgments: The aesthetic episode-Developments and challenges in empirical aesthetics. British Journal of Psychology, 105, 443-464. https://doi.org/10.1111/bjop.12084

Leder, H., Tinio, P. P. L., \& Bar, M. (2011). Emotional valence modulates the preference for curved objects. Perception, 40(6), 649-655. https://doi.org/10.1068/p6845

Liefooghe, B., \& Verbruggen, F. (2019). On the Assimilation of Instructions: Stimulus-response Associations are Implemented but not Stimulus-task Associations. Journal of Cognition, 2(1), 1-16. https://doi.org/10.5334/joc.78

Makin, A. D J. (2017). The Gap Between Aesthetic Science and Aesthetic Experience. Journal of Consciousness Studies, 24, 184-213. http://www.aesthetics.mpg.de/

Makin, A. D. J., Pecchinenda, A., \& Bertamini, M. (2012). Implicit Affective Evaluation of Visual Symmetry. Emotion, 12(5), 1021. https://doi.org/10.1037/a0026924

Mastandrea, S., Bartoli, G., \& Carrus, G. (2011). The Automatic Aesthetic Evaluation of Different Art and Architectural Styles. Psychology of Aesthetics, Creativity, and the Arts, 5(2), 126-134. https://doi.org/10.1037/a0021126

Mastandrea, S., \& Maricchiolo, F. (2014). Implicit and Explicit Aesthetic Evaluation of Design Objects. Art \& Perception, 2(1-2), 141-162. https://doi.org/10.1163/2213491300002015

Mathôt, S., Schreij, D., \& Theeuwes, J. (2012). OpenSesame: an open-source, graphical experiment builder for the social sciences. Behavior Research Methods, 44(2), 314-324. https://doi.org/10.3758/s13428-011-0168-7

Mayer, S., \& Landwehr, J. R. (2018). Quantifying visual aesthetics based on processing fluency theory: Four algorithmic measures for antecedents of aesthetic preferences. Psychology of Aesthetics, Creativity, and the Arts, 12(4), 399-431. https://doi.org/10.1037/aca0000187

Meiran, N., Cole, M. W., \& Braver, T. S. (2012). When planning results in loss of control: 
intention-based reflexivity and working-memory. Frontiers in Human Neuroscience, 6(May 2012), 104. https://doi.org/10.3389/fnhum.2012.00104

Meiran, N., Liefooghe, B., \& De Houwer, J. (2017). Powerful Instructions: Automaticity Without Practice. Current Directions in Psychological Science, 26(6), 509-514. https://doi.org/10.1177/0963721417711638

Meiran, N., Pereg, M., Kessler, Y., Cole, M. W., \& Braver, T. S. (2015). The power of instructions: Proactive configuration of stimulus-response translation. Journal of Experimental Psychology: Learning Memory and Cognition, 41(3), 768-786. https://doi.org/10.1037/xlm0000063

Mierke, J., \& Klauer, K. C. (2003). Method-Specific Variance in the Implicit Association Test. Journal of Personality and Social Psychology, 85(6), 1180-1192. https://doi.org/10.1037/0022-3514.85.6.1180

Miller, C. A., \& Hübner, R. (2020). Two Routes to Aesthetic Preference, One Route to Aesthetic Inference. Psychology of Aesthetics, Creativity, and the Arts, 14(2), 237-249. https://doi.org/10.1037/aca0000241

Munar, E., Gómez-Puerto, G., Call, J., \& Nadal, M. (2015). Common Visual Preference for Curved Contours in Humans and Great Apes. PLoS ONE, 10(11), e0141106. https://doi.org/10.1371/journal.pone.0141106

Nadal, M., Munar, E., Marty, G., \& Cela-Conde, C. (2010). Visual complexity and beauty appreciation: Explaining the divergence of results. Empirical Studies of the Arts, 28(2). https://doi.org/10.2190/EM.28.2.d

Neta, M., \& Whalen, P. J. (2010). The Primacy of Negative Interpretations When Resolving the Valence of Ambiguous Facial Expressions. Psychological Science, 21(7), 901-907. https://doi.org/10.1177/0956797610373934

Nosek, B. A. (2005). Moderators of the Relationship Between Implicit and Explicit Evaluation. Journal of Experimental Psychology: General, 134(4), 565-584. 
https://doi.org/0.1037/0096-3445.134.4.565

Nosek, B. A., \& Smyth, F. L. (2007). A Multitrait-Multimethod Validation of the Implicit Association Test: Implicit and explicit attitudes are related but distinct constructs. Experimental Psychology, 54(1), 14-29. https://doi.org/10.1027/1618-3169.54.1.14

Open Science Collaboration. (2015). Estimating the reproducibility of psychological science. Science, 349(6251), 910-911. https://doi.org/10.1126/science.aac4716

Palumbo, L., Ruta, N., \& Bertamini, M. (2015). Comparing angular and curved shapes in terms of implicit associations and approach/avoidance responses. PLOS ONE, 10(10), e0140043. https://doi.org/10.1371/journal.pone.0140043

Pavlović, M., \& Marković, S. (2012). Automatic processes in aesthetic judgment: Insights from the Implicit Association Test. PSIHOLOGIJA, 45(4), 377-393. https://doi.org/10.2298/PSI1204377P

Pecchinenda, A., Bertamini, M., Makin, A. D. J., \& Ruta, N. (2014). The Pleasantness of Visual Symmetry: Always, Never or Sometimes. PLoS ONE, 9(3), e92685. https://doi.org/10.1371/journal.pone.0092685

Pittard, N., Ewing, M., \& Jevons, C. (2007). Aesthetic theory and logo design: Examining consumer response to proportion across cultures. International Marketing Review, 24(4), 457-473. https://doi.org/10.1108/02651330710761026

R Core Team (2018). R: A language and environment for statistical computing. R Foundation for Statistical Computing, Vienna, Austria. URL https://www.R-project.org/

Reber, R. (2002). Reasons for the preference for symmetry. Behavioral and Brain Sciences, 25(3), 415-416. https://doi.org/10.1017/S0140525X02350076

Reber, R., Wurtz, P., \& Zimmermann, T. D. (2004). Exploring "fringe" consciousness: The subjective experience of perceptual fluency and its objective bases. Consciousness and Cognition, 13, 47-60. https://doi.org/10.1016/S1053-8100(03)00049-7

Ross, L., \& Ward, A. (1996). Naive realism in everyday life: Implications for social conflict and 
misunderstanding. In E. S. Reed, E. Turiel, \& T. Brown (Eds.), Values and Knowledge (The Jean P, pp. 103-135). Lawrence Erlbaum Associates, Inc.

Rothermund, K., Teige-Mocigemba, S., Gast, A., \& Wentura, D. (2009). Minimizing the influence of recoding in the Implicit Association Test: The Recoding-Free Implicit Association Test (IAT-RF). The Quarterly Journal of Experimental Psychology, 62(1), 84-98.

https://doi.org/10.1080/17470210701822975

Royer, F. L. (1981). Detection of Symmetry. Journal of Experimental Psychology: Human Perception and Performance, 7(6), 1186-1210. https://doi.org/10.1037/0096-1523.7.6.1186

Salgado-Montejo, A., Salgado, C. J., Alvarado, J., \& Spence, C. (2016). Simple lines and shapes are associated with, and communicate, distinct emotions. Cognition and Emotion, 9931(April), 1-15. https://doi.org/10.1080/02699931.2015.1133401

Silvia, P. J., \& Barona, C. M. (2009). Do People Prefer Curved Objects? Angularity, Expertise, and Aesthetic Preference. Empirical Studies of the Arts, 27(1), 25-42. https://doi.org/10.2190/EM.27.1.b

Skov, M., \& Nadal, M. (2019). The nature of perception and emotion in aesthetic appreciation: A response to Makin's challenge to empirical aesthetics. Psychology of Aesthetics, Creativity, and the Arts. Advance online publication. https://doi.org/10.1037/aca0000278

Street, N., Forsythe, A. M., Reilly, R., Taylor, R., \& Helmy, M. S. (2016). A Complex Story: Universal Preference vs. Individual Differences Shaping Aesthetic Response to Fractals Patterns. Frontiers in Human Neuroscience, 10(May), 1-14. https://doi.org/10.3389/fnhum.2016.00213

Suchotzki, K., Verschuere, B., Crombez, G., \& De Houwer, J. (2013). Reaction time measures in deception research: Comparing the effects of irrelevant and relevant stimulus-response compatibility. Acta Psychologica, 144(2), 224-231. https://doi.org/10.1016/j.actpsy.2013.06.014

Teige-Mocigemba, S., Klauer, K. C., \& Sherman, J. W. (2010). A practical guide to implicit 
Running head: PREFERENCE FOR SYMMETRY AND CURVATURE

association tests and related tasks. In B. Gawronski \& K. Payne (Eds.), Handbook of implicit social cognition: Measurement, theory, and applications (pp. 117-139). The Guildford Press.

Tinio, P. P. L., \& Leder, H. (2009). Just how stable are stable aesthetic features? Symmetry, complexity, and the jaws of massive familiarization. Acta Psychologica, 130(3), 241-250. https://doi.org/10.1016/j.actpsy.2009.01.001

Viengkham, C., \& Spehar, B. (2018). Preference for fractal-scaling properties across synthetic noise images and artworks. Frontiers in Psychology, 9(Aug), 1-19.

https://doi.org/10.3389/fpsyg.2018.01439

Weichselbaum, H., Leder, H., \& Ansorge, U. (2018). Implicit and Explicit Evaluation of Visual Symmetry as a Function of Art Expertise. I-Perception, 9(2), 1-24.

https://doi.org/10.1177/2041669518761464

Wilson, A., \& Chatterjee, A. (2005). The Assessment of Preference for Balance: Introducing a New Test. Empirical Studies of the Arts, 23(2), 165-180. https://doi.org/10.2190/B1LRMVF3-F36X-XR64 